\title{
Tauroursodeoxycholic acid inserts the bile salt export pump into canalicular membranes of cholestatic rat liver
}

\author{
Frank Dombrowski ${ }^{1}$, Bruno Stieger ${ }^{2}$ and Ulrich Beuers ${ }^{3}$ \\ ${ }^{1}$ Department of Pathology, University of Magdeburg, Magdeburg, Germany; ${ }^{2}$ Division of Clinical \\ Pharmacology, University Hospital Zurich, Zurich, Switzerland and ${ }^{3}$ Department of Medicine \\ II-Grosshadern, Klinikum of the University of Munich, Munich, Germany
}

\begin{abstract}
Ursodeoxycholic acid exerts anticholestatic effects in chronic cholestatic liver disease in humans as well as in experimental animal models of cholestasis. Its taurine conjugate, TUDCA, was recently shown to stimulate insertion of the apical conjugate export pump, Mrp2 (ABCC2), into canalicular membranes of rat hepatocytes made cholestatic by exposure to taurolithocholic acid (TLCA). The aim of this immunoelectronmicroscopic study was to test whether TLCA and TUDCA modulate the canalicular density of the other key apical transporter, the bile salt export pump, Bsep (ABCB11), in a similar way. Immunoelectronmicroscopic analysis of Bsep density on canalicular membranes, microvilli, and pericanalicular area of hepatocytes was performed in rat liver tissue prepared after liver perfusion with bile acids or carrier medium only. TLCA (10 $\mu \mathrm{mol} / \mathrm{l}$ for $50 \mathrm{~min})$ decreased Bsep density in canalicular membranes to $31 \%$ of controls $(P<0.05)$ when bile flow was reduced to $35 \%$ of controls $(P<0.05)$. Concomitantly, Bsep density in a $1 \mu \mathrm{m}$ pericanalicular zone increased to $202 \%$ $(P<0.05)$ indicating effective retrieval of Bsep from the canalicular membrane induced by TLCA. Coadministration of TUDCA $(25 \mu \mathrm{mol} / \mathrm{l})$ led to a 3.2-fold increase of Bsep density in canalicular membranes equal to control liver $(P<0.05$ vs TLCA) in association with a 3.8-fold increase of bile flow $(P<0.05$ vs TLCA). Stimulation of apical membrane insertion of key transporters like the bile salt export pump, Bsep, and-as previously shownthe conjugate export pump, Mrp2, may contribute to the anticholestatic action of UDCA amides in cholestatic conditions.
\end{abstract}

Laboratory Investigation (2006) 86, 166-174. doi:10.1038/labinvest.3700371; published online 12 December 2005

Keywords: cholestasis; bile acids; ursodeoxycholic acid; exocytotic insertion; retrieval

The hydrophilic bile acid ursodeoxycholic acid (UDCA) improves serum liver tests, delays histological progression, and may prolong transplant-free survival in patients with chronic cholestatic liver diseases like primary biliary cirrhosis. ${ }^{1}$ Anticholestatic effects of UDCA are also observed in experimental models of cholestasis ${ }^{1-6}$ The mechanisms of action of UDCA are incompletely understood so far. However, post-translational stimulation of hepatobiliary secretion by activation of complex intracellular signaling pathways is regarded as one key mechanism of action of UDCA in cholestasis. ${ }^{1-6}$

We have recently reported that the cholestatic bile acid taurolithocholic acid (TLCA) reduces the

Correspondence: Professor U Beuers, MD, Department of Medicine II-Grosshadern, Klinikum of the University of Munich, Marchioninistraße 15, 81377 Munich, Germany.

E-mail: beuers@med.uni-muenchen.de

Received 6 May 2005; revised and accepted 13 October 2005; published online 12 December 2005 density of the apical conjugate export pump, Mrp2 (ABCC2), in canalicular membranes of rat livers and markedly impairs organic anion secretion into bile, ${ }^{7}$ in part by phosphatidylinositol 3-kinase (PI3K)dependent mechanisms. ${ }^{8}$ The taurine conjugate of UDCA (TUDCA) reversed the cholestatic effect of TLCA on bile formation, normalized Mrp2 density in canalicular membranes of cholestatic hepatocytes, and stimulated organic anion secretion into bile in part by protein kinase C (PKC)-dependent mechanisms. ${ }^{7}$ In line with these observations, TUDCA also protected against TLCA-induced impairment of bile acid secretion in hepatocyte couplets by a PKC-dependent mechanism. ${ }^{9}$ Thus, we speculated that TUDCA may trigger insertion also of other key transporters like the bile salt export pump, Bsep (ABCB11), into the apical membrane, thereby contributing to relief of secretory damage in cholestatic hepatocytes.

Bile acids are the major driving force for generation of bile flow. The apical bile salt export pump, 
Bsep, mediates excretion of bile acids from liver cells into bile. It is expressed in the rat canalicular plasma membrane of hepatocytes and in subcanalicular intracellular vesicles. ${ }^{10}$ In normal liver, Bsep targeting towards the apical membrane has been shown to be stimulated by TUDCA via an integrindependent dual signaling pathway which involves activation of $\mathrm{p} 38^{\mathrm{MAPK}}$ and $\mathrm{p} 44 / 42^{\mathrm{MAPK}}{ }^{6,11-13}$ However, this mechanism might be less effective in experimental cholestasis. ${ }^{14,15}$ Thus, it remains unclear whether TUDCA modulates insertion of key apical carriers other than Mrp2 in cholestatic liver. Indeed, Bsep was shown recently to traffic directly from the Golgi to the canalicular domain ${ }^{16,17}$ whereas targeting of Mrp2 is less clear: most apical proteins such as the pIgA receptor (pIgA-R) take a transcytotic route from the Golgi to the basolateral and then the apical membrane,${ }^{18}$ and Mrp2 has been localized in vesicles cotransporting pIgA-R. ${ }^{19}$ In addition, Mrp2, but not Bsep, has been shown to be partially and reversibly relocated from the canalicular to the basolateral domain of hepatocytes after lipopolysacharide exposure. ${ }^{20}$ Thus, sorting of Mrp2 and Bsep may be differently regulated. ${ }^{17}$ Therefore, we extended our previous immunoelectronmicroscopic investigation by studying density of Bsep in canalicular membranes (without microvilli), canalicular microvilli, and the pericanalicular zone of liver tissue of normal rat livers, rat livers made cholestatic by administration of TLCA and those treated with both, TLCA and TUDCA, identical to those reported recently. ${ }^{7}$

\section{Materials and methods}

\section{Materials}

Fish gelatine was from Aurion (Amsterdam, The Netherlands). Lowicryl K4M was from Polysciences (Warrington, PA, USA). A polyclonal antibody raised against the carboxy terminal end of the rat Bsep was characterized previously. ${ }^{10}$ A goat-antirabbit antibody conjugated with $10 \mathrm{~nm}$ gold particles was from Jackson ImmunoResearch Laboratories Inc. (West Grove, PA, USA). A carbon-filmed 200mesh $3 \mathrm{~mm}$ copper grid was from Plano (Wetzlar, Germany). All other chemicals were of the highest purity commercially available.

\section{Isolated Rat Liver Perfusion}

The technical procedure has been described in detail previously. ${ }^{7}$ After anesthesia with sodium pentobarbital $(50 \mathrm{mg} / \mathrm{kg}$ body wt i.p.), preparation and cannulation of the portal vein, rat livers were perfused with Krebs-Ringer bicarbonate solution at $37^{\circ} \mathrm{C}$ (KRB: $\mathrm{NaCl} 118 \mathrm{mmol} / \mathrm{l}, \mathrm{KCl} 4.8 \mathrm{mmol} / \mathrm{l}$, $\mathrm{NaHCO}_{3} 25 \mathrm{mmol} / \mathrm{l}, \quad \mathrm{KH}_{2} \mathrm{PO}_{4} 1.2 \mathrm{mmol} / \mathrm{l}, \quad \mathrm{MgSO}_{4}$ $1.2 \mathrm{mmol} / \mathrm{l}, \mathrm{CaCl}_{2} 1.9 \mathrm{mmol} / \mathrm{l}$, D-glucose $5.5 \mathrm{mmol} / \mathrm{l}$, $\mathrm{pH} \quad 7.4$; gassed with $95 \% \quad \mathrm{O}_{2} / 5 \% \quad \mathrm{CO}_{2}$ by an oxygenator) at a constant flow rate of $3.5 \mathrm{ml} / \mathrm{min} / \mathrm{g}$ liver. Livers were then preloaded with horseradish peroxidase (HRP, $0.05 \mathrm{mg} / \mathrm{ml}$ ) for $25 \mathrm{~min}$ in a recirculating $\mathrm{KRB}$ perfusion $(32 \mathrm{ml} / \mathrm{min})$ containing $1 \mathrm{~g} / \mathrm{dl}$ bovine serum albumin (BSA) to avoid adherence of HRP to glassware and tubing and protect livers against potential accumulating toxins during recirculation. The perfusion was then switched to a nonrecirculating HRP- and BSA-free KRB perfusion and residual HRP in the vascular bed was washed out for 5 min. ${ }^{7}$ The cholestatic bile acid TLCA $(10 \mu \mathrm{mol} / \mathrm{l})$, both TLCA $(10 \mu \mathrm{mol} / \mathrm{l})$ and TUDCA (25 $\mu \mathrm{mol} / \mathrm{l}$ ), or carrier medium only (DMSO, $0.1 \%$, $\mathrm{v} / \mathrm{v}$ ) were continuously administered for $50 \mathrm{~min}$ as described in detail previously. ${ }^{7}$ Livers were then perfused with a fixation buffer $(\mathrm{NaCl} 137 \mathrm{mmol} / \mathrm{l}$, $\mathrm{Na}_{2} \mathrm{HPO}_{4} \quad 7.8 \mathrm{mmol} / \mathrm{l}, \quad \mathrm{KH}_{2} \mathrm{PO}_{4} \quad 1.5 \mathrm{mmol} / \mathrm{l}, \quad \mathrm{KCl}$ $2.7 \mathrm{mmol} / \mathrm{l}, \mathrm{pH} 7.4 ; 3 \%(\mathrm{w} / \mathrm{v})$ paraformaldehyde, $3 \%(\mathrm{w} / \mathrm{v})$ dextrane $40000 \mathrm{Da} ; 0.3 \%(\mathrm{w} / \mathrm{v})$ glutaraldehyde) for $5 \mathrm{~min}$ until stiffness and were removed. Slices of about $1 \mathrm{~mm}$ thickness were cut and incubated for immunoelectronmicroscopic studies in phosphate-buffered solution (PBS) ( $\mathrm{NaCl} 137 \mathrm{mmol} / \mathrm{l}$, $\mathrm{Na}_{2} \mathrm{HPO}_{4} \quad 7.8 \mathrm{mmol} / \mathrm{l}, \quad \mathrm{KH}_{2} \mathrm{PO}_{4} 1.5 \mathrm{mmol} / \mathrm{l}, \quad \mathrm{KCl} 2.7$ $\mathrm{mmol} / \mathrm{l}, \mathrm{pH}$ 7.4). Samples were stored at $4^{\circ} \mathrm{C}$ until shipping (same or next day).

\section{Immunoelectronmicroscopic Studies}

Tissue preparation, immunoelectronmicroscopic studies, and blinded morphometric analysis were exactly performed as described recently. ${ }^{7}$ Four cubes of $0.5 \mathrm{~mm}$ per liver were embedded in Lowicryl K4M following a number of incubation steps in PBS (0.1 mmol/l, $\mathrm{pH} 7.6): 30 \mathrm{~min}$ ethanol $(30 \%, \mathrm{v} / \mathrm{v})$ at $4{ }^{\circ} \mathrm{C}$; $1 \mathrm{~h}$ ethanol $(50 \%, \mathrm{v} / \mathrm{v})$ at $4^{\circ} \mathrm{C} ; 1 \mathrm{~h}$ ethanol $(70 \%$, $\mathrm{v} / \mathrm{v})$ at $4{ }^{\circ} \mathrm{C} ; 1 \mathrm{~h}$ ethanol $(90 \%, \mathrm{v} / \mathrm{v})$ at $-35^{\circ} \mathrm{C} ; 1 \mathrm{~h}$ ethanol $(100 \%)$ at $-35^{\circ} \mathrm{C} ; 20 \mathrm{~h}$ Lowicryl/ethanol (1:1) at $-35^{\circ} \mathrm{C} ; 24 \mathrm{~h}$ Lowicryl/ethanol $(2: 1)$ at $-35^{\circ} \mathrm{C}$; $24 \mathrm{~h}$ Lowicryl at $-35^{\circ} \mathrm{C} ; 24 \mathrm{~h}$ polymerization under UV light at $-35^{\circ} \mathrm{C} ; 72 \mathrm{~h}$ polymerization under UV light at $21^{\circ} \mathrm{C}$. Thin sections were prepared from two tissue blocks of each liver with an ultramicrotome system (2128 Ultrotome, LKB, Sweden). Sections were placed on a carbon-filmed 200-mesh $3 \mathrm{~mm}$ copper grid.

A total of 10 thin sections were prepared simultaneously in PBS (0.1 mmol/l, pH 7.6): $15 \mathrm{~min} 0.05 \mathrm{~mol} / \mathrm{l}$ glycine (aldehyde block); 30 min $5 \%$ goat serum $+5 \%$ bovine serum albumin (BSA) $+0.1 \%$ cold washed fish gelatine (protein block); $3 \times 5 \mathrm{~min} 0.1 \%$ BSA (washing); $1 \mathrm{~h}$ Bsep antibody ${ }^{9}$ diluted 1:500 (primary antibody); $3 \times 5$ min $0.1 \%$ BSA (washing); $2 \mathrm{~h}$ goat-antirabbit antibody conjugated with $10 \mathrm{~nm}$ gold diluted 1:20 (secondary antibody); $3 \times 5 \mathrm{~min} \quad 0.1 \%$ BSA (washing); 5 min PBS (washing); $10 \mathrm{~min} 2 \%$ glutaraldehyde (fixation); $3 \times 5 \mathrm{~min} 0.1 \%$ BSA (washing); 5 min PBS (washing); 5 min 2\% uranyl acetate (contrast); $5 \times 1 \mathrm{~min}$ aqua bidest (washing); $5 \mathrm{~s} \mathrm{~Pb}-$ citrate (contrast); $10 \mathrm{~s}$ aqua bidest (wash). ${ }^{7}$ 


\section{Morphometric Analysis}

Tissue specimens were blinded in order to avoid a bias during morphometric analysis as described previously. ${ }^{7}$ The analytical protocol was determined a priori. Thin sections were viewed with a CM10 electron microscope (Phillips, Einthoven, The Netherlands). Fields in the acinar zone 2 were only chosen at a low magnification $(\times 700)$ considering the variability of bile canalicular size between different zones $^{21}$ as well as the variability of transcellular bile acid transport from one zone to another. ${ }^{22}$ The quality of immunohistochemical staining was checked for every test field, and fields with background staining of mitochondria, nucleus, or sinusoid were excluded. Micrographs were taken at magnifications of $\times 15500$ and photo prints were enlarged to final magnifications of $\times 40000$. Gold dots were typically identified only within a 'pericanalicular zone' defined as a zone of $1 \mu \mathrm{m}$ around the bile canaliculus. For semiquantitative analysis, a line of $4 \mathrm{~cm}$ (equal to $1 \mu \mathrm{m}$ of original size) was drawn by hand around the canaliculus on photo prints of magnification $\times 40000$. Gold dots in this 'pericanalicular zone', on the canalicular membrane (without microvilli), and on the microvilli were separately counted. ${ }^{7}$

A square point lattice system consisting of 12 lines and 144 points was superimposed on the photo prints. All points on the pericanalicular zone and on the canalicular lumen were counted as a measure of the relative areas covered by pericanalicular zone and canaliculus. The intersections at which parallel lines crossed the canalicular membrane or the microvilli within the canaliculus were counted separately as a measure of the relative surface area of the canaliculus. ${ }^{23,24}$

\section{Statistical Analysis}

Results are expressed as mean \pm standard deviation (s.d. ). Data were compared between groups using an unpaired two-tailed Student's $t$-test. $P<0.05$ was considered statistically significant.

\section{Results}

\section{Bile Flow}

In control livers, bile flow was $0.72 \pm 0.09 \mu \mathrm{l} / \mathrm{min} / \mathrm{g}$ liver $(n=5 ; \mathrm{DMSO}, 0.1 \%, \mathrm{v} / \mathrm{v})$ at the end of an
80 min perfusion period prior to tissue preparation for immunoelectronmicroscopic studies. ${ }^{7}$ TLCA $(10 \mu \mathrm{mol} / \mathrm{l}$ (min 31-min 80$)$ ) reduced bile flow to $35 \%$ of controls $\left(n=4 ; P<0.05\right.$; Table $\left.1^{7}\right)$ prior to tissue preparation. Coadministration of TLCA and TUDCA $(25 \mu \mathrm{mol} / \mathrm{l}$ (min $31-\mathrm{min} 80)$ ) increased bile flow to $133 \%$ of controls $(n=5 ; P<0.05$ vs TLCA alone; Table $1^{7}$ ).

\section{HRP Secretion}

In control livers, HRP secretion was $0.16+0.11 \mathrm{ng} /$ $\mathrm{min} / \mathrm{g}$ liver $(n=5$; DMSO, $0.1 \%, \mathrm{v} / \mathrm{v})$ at the end of an $80 \mathrm{~min}$ perfusion period prior to tissue preparation for immunoelectronmicroscopic studies. ${ }^{7}$ TLCA $(10 \mu \mathrm{mol} / \mathrm{l}(\min 31-\min 80))$ reduced HRP secretion to $33 \%$ of controls $(n=4 ; P<0.05$ vs control; Table $\left.1 .^{7}\right)$ prior to tissue preparation. Coadministration of TLCA and TUDCA (25 $\mu \mathrm{mol} / \mathrm{l}$ (min 31-min 80)) increased HRP secretion to $88 \%$ of controls $(n=5$; $P<0.05$ vs TLCA alone; Table $1 .^{7}$ ).

\section{Morphometric Analysis of Pericanalicular Area of Mid-Zonal (Zone 2) Hepatocytes}

Bile canalicular size varies between periportal (zone 1), mid-zonal (zone 2), and pericentral (zone 3) areas. ${ }^{21}$ In addition, variability of transcellular bile acid transport from one zone to another has been described. ${ }^{22}$ Therefore, only mid-zonal pericanalicular areas were chosen for morphometric analysis in the present study in order to limit variability of experimental conditions. The volume of the canalicular lumen as well as the surface area of canalicular and microvilli membranes did not change significantly in comparison to DMSO controls when TLCA or TLCA + TUDCA were administered (Table 2). The volume of the pericanalicular zone remained unaffected by TLCA, but slightly increased when TUDCA and TLCA were administered concomitantly (Table 2).

\section{Bsep Density in Canalicular Membranes}

Bsep density in canalicular membranes (without microvilli) of control livers was $2.4 \pm 1.3 \mathrm{AU}(n=5)$. Administration of TLCA $(10 \mu \mathrm{mol} / \mathrm{l}$ for $50 \mathrm{~min})$ led to a decrease of Bsep density in canalicular membranes to $31 \%$ of controls $(P=0.04$; Figure 1 b, 2a;

Table 1 Bile flow and biliary secretion of HRP in isolated perfused rat liver treated with DMSO (0.1\%, v/v, control), TLCA (10 $\mu \mathrm{mol} / \mathrm{l})$, and TLCA $(10 \mu \mathrm{mol} / \mathrm{l})+$ TUDCA $(25 \mu \mathrm{mol} / \mathrm{l}){ }^{7}$

\begin{tabular}{|c|c|c|c|}
\hline (n) & DMSO (5) & TLCA $(10 \mu \mathrm{mol} / \mathrm{l})(4)$ & TLCA $(10 \mu \mathrm{mol} / \mathrm{l})+T U D C A(25 \mu \mathrm{mol} / \mathrm{l})(5)$ \\
\hline Bile flow ( $\mu \mathrm{l} / \mathrm{min} / \mathrm{g}$ liver $)$ & $0.70 \pm 0.08$ & $0.25 \pm 0.08^{*}$ & $0.96 \pm 0.18^{\#}$ \\
\hline HRP secretion (ng/min/g liver) & $0.155 \pm 0.110$ & $0.051 \pm 0.014^{*}$ & $0.137 \pm 0.014^{\#}$ \\
\hline
\end{tabular}

Results are given as mean \pm s.d. of $4-5$ experiments each. ${ }^{*} P<0.05$ vs control, ${ }^{*} P<0.05$ vs TLCA alone, unpaired two-tailed Student's $t$-test. 
Table 2 Morphometric analysis of (peri-)canalicular area of zone 2 hepatocytes from livers treated with DMSO (0.1\%, v/v), TLCA $(10 \mu \mathrm{mol} / \mathrm{l})$, or TLCA $(10 \mu \mathrm{mol} / \mathrm{l})+$ TUDCA $(25 \mu \mathrm{mol} / / \mathrm{l})$, each for $50 \mathrm{~min}$

\begin{tabular}{|c|c|c|c|}
\hline (n) & DMSO (control) (5) & $T L C A(10 \mu \mathrm{mol} / \mathrm{l})(4)$ & $\begin{array}{c}\text { TLCA }(10 \mu \mathrm{mol} / \mathrm{l})+T U D C A \\
(25 \mu \mathrm{mol} / \mathrm{l})(5)\end{array}$ \\
\hline \multicolumn{4}{|l|}{ Arbitrary units (AU) } \\
\hline Pericanalicular zone $(1 \mu \mathrm{m})$ volume & $52.2 \pm 6.3$ & $58.9 \pm 3.2$ & $61.8 \pm 6.1^{*}$ \\
\hline Canalicular lumen volume & $14.8 \pm 3.1$ & $17.7 \pm 3.5$ & $17.4 \pm 5.2$ \\
\hline $\begin{array}{l}\text { Canalicular membrane (without } \\
\text { microvilli) surface area }\end{array}$ & $11.0 \pm 2.4$ & $9.8 \pm 2.5$ & $10.7 \pm 1.3$ \\
\hline Microvilli surface area & $17.3 \pm 2.0$ & $19.7 \pm 2.8$ & $19.5 \pm 6.0$ \\
\hline
\end{tabular}

Liver tissue was fixed immediately after perfusion. Morphometric analysis was performed by electronmicroscopy at a magnification of $\times 40000$ according to Weibel et $a l^{23}$ and Weibel. ${ }^{24}$ For experimental details, see also Methods. ${ }^{7}$ Results are given as mean \pm s.d. of $4-5$ tissue samples in arbitrary units of volume or area, (each single data point represents a mean of six measurements per tissue sample). ${ }^{*} P<0.05$ vs control, unpaired two-tailed Student's $t$-test.

Table 3). Coadministration of TUDCA $(25 \mu \mathrm{mol} / \mathrm{l})$ led to a significant 3.2-fold increase of Bsep density in canalicular membranes (98\% of controls; $P=0.02$ vs TLCA alone; Figure 1, 2; Table 3). Similar observations had recently been made in identical liver preparations for Mrp2 (Figure 2b, Table 3). ${ }^{7}$

\section{Bsep Density on Canalicular Microvilli}

Bsep density on canalicular microvilli of control livers was $6.8 \pm 2.6$ AU $(n=5)$. Interestingly, the density of Bsep on canalicular microvilli was reduced by TLCA to $47 \%$ of controls $(P=0.03)$, and this effect was not reversed by coadministration of TUDCA within the perfusion period of $50 \mathrm{~min}$ (Figure 1; Table 3). These findings differed from those for Mrp2 in identical liver preparations (Figure 2b, Table 3). ${ }^{7}$

\section{Bsep Density in the Pericanalicular Zone}

Bsep density in the pericanalicular zone (defined as an area of $1 \mu \mathrm{m}$ around the canaliculus) of control livers was $3.3+1.7 \mathrm{AU}(n=5)$. Bsep density in the pericanalicular zone increased after administration of TLCA to $202 \%$ of controls $(P=0.03)$. Coadministration of TUDCA for 50 min did not markedly alter Bsep density in the pericanalicular zone (Figure 1; Table 3). These findings differed from those for Mrp2 in identical liver preparations for which no significant changes had been observed (Figure 2b, Table 3). ${ }^{7}$

\section{Bsep vs Mrp2 Density in Pericanalicular and Canalicular Area}

The present data together with those published recently $^{7}$ indirectly suggest that comparable amounts of Bsep and Mrp2 are expressed in the pericanalicular and canalicular areas of mid-zonal hepatocytes of rat liver (Table 3), although immunoelectron microscopy was not calibrated for Bsep antibody to Mrp2 antibody in this study. In control livers, the total number of gold dots labeling Bsep was $12.7 \pm 3.0(n=5)$ and the total number of gold dots labeling Mrp2 was $11.5 \pm 4.1 \quad(n=6)$. This observation is in line with a previous study which demonstrated similar labeling rates for Bsep and Mrp2 in microtubule-associated vesicles from rat hepatocytes. ${ }^{19}$

\section{Discussion}

This immunoelectronmicroscopic study shows that the cholestatic bile acid, TLCA, markedly reduces the density of the bile salt export pump, Bsep, in canalicular membranes of rat liver, whereas Bsep density in the pericanalicular area was increased, suggesting TLCA-induced retrieval of Bsep from the apical hepatocyte membrane. The anticholestatic bile acid, TUDCA, reversed the effect of TLCA on Bsep density in canalicular membranes and mediated insertion of Bsep into canalicular membranes of cholestatic rat liver along with stimulation of bile flow, vesicular exocytosis, and organic anion secretion in the same experimental model as reported recently. ${ }^{7,8}$ These data complement and corroborate our previous immunoelectronmicroscopic findings which showed that TUDCA stimulates insertion of another key apical carrier, the conjugate export pump, Mrp2, into its target membrane in bile acid-induced cholestasis. ${ }^{7}$ Bile acids and Mrp2 substrates such as glutathione conjugates represent the major driving forces of bile formation. Therefore, stimulation of Bsep and Mrp2 insertion into canalicular membranes may contribute to the anticholestatic effect of UDCA amides in cholestasis.

The exact molecular mechanism by which TUDCA stimulates exocytotic fusion of vesicles at the apical membrane $e^{7,25}$ and apical carrier insertion ${ }^{7,12,13}$ remains elusive. Various signaling molecules including isoforms of PKC, ${ }^{7,9,13}$ cytosolic-free calcium $\left(\mathrm{Ca}^{2+}\right)_{\mathrm{i}},{ }^{9,25}$ mitogen-activated protein (MAP) kinases p38 ${ }^{\mathrm{MAPK} 6,12,13}$ and p44/42 ${ }^{\mathrm{MAPK}},{ }^{11,14}$ src kinase $^{6}$ as well as PI3K ${ }^{8,26-28}$ have been shown to be involved in bile acid-dependent hepatobiliary exocytosis and carrier 

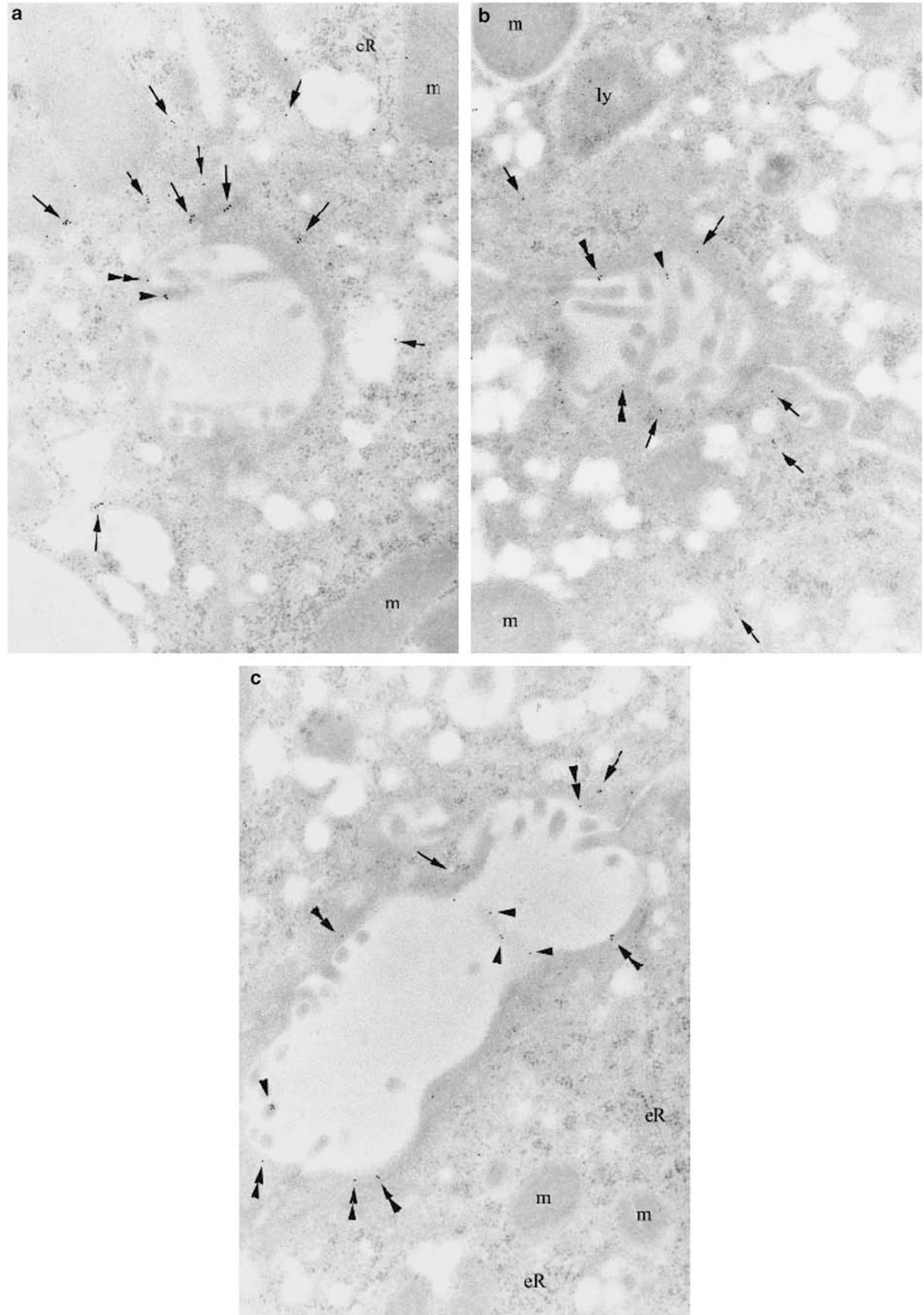
Table 3 Morphometric analysis of distribution of the bile salt export pump, Bsep, in (peri-)canalicular area from livers treated with DMSO $(0.1 \%, \mathrm{v} / \mathrm{v})$, TLCA $(10 \mu \mathrm{mol} / \mathrm{l})$, or TLCA $(10 \mu \mathrm{mol} / \mathrm{l})+$ TUDCA $(25 \mu \mathrm{mol} / / \mathrm{l})$, each for $50 \mathrm{~min}$

\begin{tabular}{|c|c|c|c|}
\hline $\begin{array}{c}\left(\mathrm{n}_{\text {Bsep }}\right) \\
\left(\mathrm{n}_{\text {Mrp } 2}\right)\end{array}$ & $\begin{array}{l}\text { Control } \\
\text { (5) } \\
\text { (6) }\end{array}$ & $\begin{array}{c}\text { TLCA }(10 \mu \mathrm{mol} / \mathrm{l}) \\
(4) \\
(4)\end{array}$ & $\begin{array}{c}\text { TLCA }(10 \mu \mathrm{mol} / \mathrm{l})+T U D C A(25 \mu \mathrm{mol} / \mathrm{l}) \\
(5) \\
(8)\end{array}$ \\
\hline \multicolumn{4}{|c|}{ Gold dots } \\
\hline \multicolumn{4}{|c|}{ Pericanalicular zone } \\
\hline Bsep & $3.3 \pm 1.7$ & $6.7 \pm 1.9^{*}$ & $6.4 \pm 3.0$ \\
\hline $\operatorname{Mrp}^{7}$ & $5.6 \pm 2.3$ & $5.8 \pm 3.2$ & $4.7 \pm 2.4$ \\
\hline \multicolumn{4}{|c|}{ Canalicular membrane } \\
\hline Bsep & $2.4 \pm 1.3$ & $0.7 \pm 0.5^{*}$ & $2.3 \pm 0.9^{\#}$ \\
\hline $\operatorname{Mrp}^{7}$ & $1.2 \pm 0.8$ & $0.3 \pm 0.3^{*}$ & $0.9 \pm 0.6^{\#}$ \\
\hline \multicolumn{4}{|l|}{ Microvilli } \\
\hline Bsep & $6.8 \pm 2.6$ & $3.2 \pm 1.4^{*}$ & $3.1 \pm 1.9^{*}$ \\
\hline $\mathrm{Mrp}^{7}$ & $4.8 \pm 1.7$ & $5.1 \pm 2.6$ & $4.0 \pm 2.3$ \\
\hline \multicolumn{4}{|c|}{ Canalicular membrane+microvilli } \\
\hline Bsep & $9.2 \pm 2.2$ & $3.9 \pm 1.6^{*}$ & $5.4 \pm 2.3^{*}$ \\
\hline $\operatorname{Mrp}^{7}$ & $8.1 \pm 6.0$ & $5.4 \pm 2.7$ & $4.9 \pm 2.9$ \\
\hline \multicolumn{4}{|c|}{ Gold dots/canalicular membrane and microvilli surface area (AU) } \\
\hline \multicolumn{4}{|c|}{ - } \\
\hline Bsep & $0.33 \pm 0.10$ & $0.14 \pm 0.04^{*}$ & $0.19 \pm 0.10$ \\
\hline $\operatorname{Mrp}^{7}$ & $0.44 \pm 0.47$ & $0.18 \pm 0.07$ & $0.19 \pm 0.10$ \\
\hline \multicolumn{4}{|c|}{ Gold dots/pericanalicular zone $(1 \mu \mathrm{m})$ volume (AU) } \\
\hline \multicolumn{4}{|c|}{ Pericanalicular area } \\
\hline Bsep & $0.07 \pm 0.04$ & $0.11 \pm 0.03$ & $0.11 \pm 0.05$ \\
\hline $\operatorname{Mrp}^{7}$ & $0.11 \pm 0.04$ & $0.10 \pm 0.05$ & $0.08 \pm 0.06$ \\
\hline \multicolumn{4}{|c|}{ (Gold dots/canalicular membrane and microvilli surface area)/(gold dots/pericanalicular zone (1 $\mu \mathrm{m}$ ) volume) (AU) } \\
\hline Bsep & $6.31 \pm 3.35$ & $1.27 \pm 0.42$ & $2.94 \pm 3.21$ \\
\hline $\operatorname{Mrp}^{7}$ & $4.58 \pm 4.94$ & $2.24 \pm 1.57$ & $3.25 \pm 2.66$ \\
\hline
\end{tabular}

insertion/retrieval in apical membranes under various experimental conditions. ${ }^{29}$

In the normal rat liver, TUDCA may trigger insertion of Bsep into canalicular membranes by a dual integrin-dependent signaling pathway which includes activation of $\mathrm{p} 44 / 42^{\mathrm{MAPK}}$ on one hand and activation of $\mathrm{p} 38^{\mathrm{MAPK}}$ on the other hand $\mathrm{d}^{6,11-13}$ Preliminary evidence suggests that this pathway may be less relevant for the anticholestatic effect of TUDCA in bile acid-induced cholestasis ${ }^{14,15}$ In TLCA-induced cholestasis, the anticholestatic effect of TUDCA appears to be mediated in part by PKC-dependent mechanisms although the exact isoform involved has not yet been determined. ${ }^{7}$
$\mathrm{PKC} \alpha$ is selectively activated by TUDCA in rat hepatocytes $^{30-32}$ and $\operatorname{PKC} \alpha$ has been shown to phosphorylate Bsep. ${ }^{33}$ The assumption that PKC $\alpha$ may mediate TUDCA-induced vesicular exocytosis in cholestatic liver ${ }^{7}$ was questioned recently, ${ }^{34}$ but further studies are needed to clarify the exact molecular mechanisms of PKC-dependent anticholestatic action of TUDCA. Interestingly, PKC was recently shown to be also involved in TUDCAinduced Bsep targeting to pseudocanaliculi in Ntcp-transfected HepG2 cells. ${ }^{13}$ Thus, the present finding that TUDCA stimulates Bsep insertion in the rat liver made cholestatic by TLCA stimulates further efforts to clarify the exact molecular

Figure 1 Immunoelectronmicroscopic demonstration of bile salt export pump (Bsep) localization in canalicular membranes (double arrowhead), microvilli (arrowhead), and pericanalicular cytoplasm (arrow) of isolated perfused rat liver. Livers were treated for 50 min with (a) DMSO alone $(0.1 \%$, v/v; control), (b) TLCA $(10 \mu \mathrm{mol} / \mathrm{l})$, or (c) TLCA $(10 \mu \mathrm{mol} / \mathrm{l})+$ TUDCA $(25 \mu \mathrm{mol} / \mathrm{l})$. At the end of each experiment, the liver was perfused with a fixation buffer and removed. Slices of liver tissue were embedded in Lowicryl without osmiumtetroxide fixation. ${ }^{7}$ The bile salt export pump, Bsep, was labeled with gold particles (black dots) and is indicated by arrows and arrowheads. A blinded morphometric analysis ${ }^{7}$ (see Results, Table 3, Figure 2) revealed significant differences in the density of Bsep in canalicular membranes under varying experimental conditions. Pale areas within the cytoplasm represent areas of glycogen (washed out) and smooth endoplasmic reticulum. Mitochondria (m), endoplasmic reticulum (eR). Original magnification $\times 40000$. 

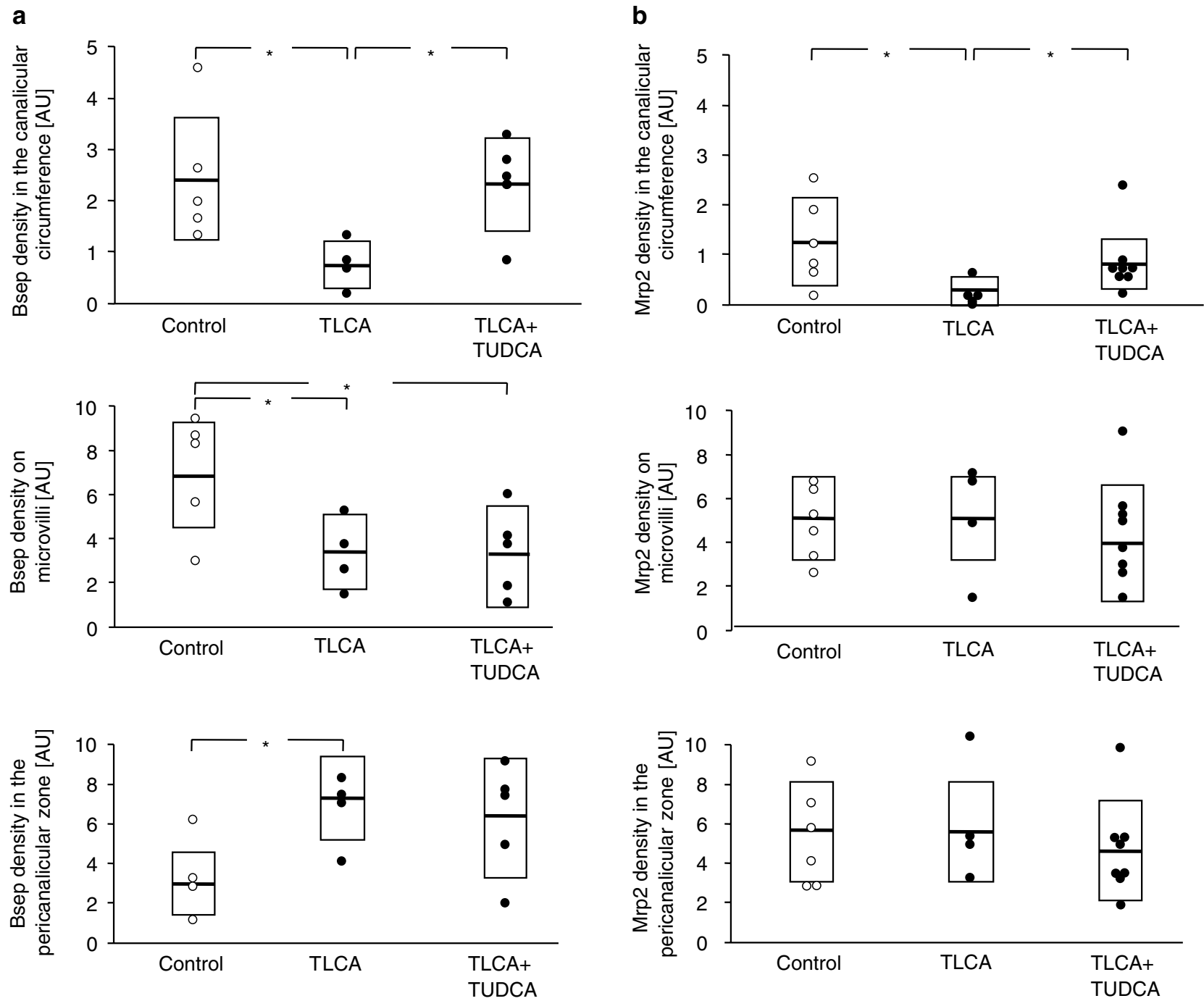

Figure 2 Effect of bile acids on (a) Bsep density and-for comparison-(b) Mrp2 density (as reported previously ${ }^{7}$ ) in the pericanalicular zone $(1 \mu \mathrm{m})$, the canalicular membranes (without microvilli), and the microvilli of zone 2 hepatocytes in the isolated perfused rat liver. Livers were treated for $50 \mathrm{~min}$ with DMSO alone ( $0.1 \%$, v/v, control), TLCA ( $10 \mu \mathrm{mol} / \mathrm{l})$, or TLCA (10 $\mu \mathrm{mol} / \mathrm{l})+$ TUDCA (25 $\mu \mathrm{mol} / \mathrm{l})$. Bsep and Mrp2 density in areas of interest was determined in a blinded fashion by immunoelectron microscopy in six canaliculi per liver as described recently. ${ }^{7}$ Results are expressed in arbitrary units and are given as mean \pm s.d. of $4-8$ experiments. ${ }^{*} P<0.05$, two-tailed unpaired Student $t$ test.

mechanisms including the role of PKC isoforms involved in apical carrier insertion by TUDCA in cholestasis.

The TLCA-induced decrease of Bsep density in the canalicular membrane and a concomitant increase of Bsep in the pericanalicular area of hepatocytes in the present study corroborate the assumption that TLCA stimulates Bsep retrieval into the cell. Interestingly, reduction of Mrp2 density in apical membranes by TLCA in the identical experimental model was not accompanied by an increase of Mrp2 in the pericanalicular area of hepatocytes. ${ }^{7}$ This difference might be explained by a limited sensitivity of the immunoelectronmicroscopic approach to detect small changes in carrier density in an area as 'large' as the pericanalicular area (defined as a $1 \mu \mathrm{m}$ zone around the canaliculus) when compared to the amount of carriers in the apical membrane. However, this difference might also confirm observations indicating that Mrp2 is largely retained at the apical membrane in differentiated hepatic cells, while Bsep undergoes dynamic endocytosis and recycles between the canalicular membrane and a subapical region ${ }^{17,35,36}$ The potential difference in the dynamics of these two carriers has been linked to differences in linkage to the actinbased cytoskeleton. While Mrp2 interacts via its PDZ domain with ezrin-radixin-moesin (ERM) proteins, ${ }^{37}$ which bind directly to actin thereby providing a tight apical retention mechanism, Bsep does not contain a PDZ domain and does probably not interact with ERM proteins. In addition, other factors such as protein membrane solubility may affect differences in carrier endocytosis. ${ }^{17,18}$ 
A relevant loss of Bsep into the bile canalicular lumen during administration of TLCA appears unlikely to explain the decrease of Bsep density in canalicular membranes. Although hydrophobic bile salts have been shown to induce external hemileaflet exocytosis of phospholipid vesicles, ${ }^{38,39}$ the mechanisms for protein retention within the canalicular membrane during biliary phospholipid secretion appear to be very effective. ${ }^{40}$ Thus, Bsep retrieval into the pericanalicular zone (see Figures 1 and 2) appears to be the predominant mechanism leading to Bsep deprivation of apical hepatocyte membranes exposed to TLCA.

TUDCA normalized Bsep (and Mrp2) density only in the canalicular circumference, whereas TLCAinduced alterations in the pericanalicular zone and on microvilli were not affected during the limited time of perfusion (Figure 2, Table 3). Changes in the membrane density of canalicular transporters during short-term exposure to the anticholestatic bile acid, TUDCA, may mainly be observed at the site of first contact of carrier-loaded vesicles with their target membrane. Vesicles carrying Bsep and Mrp2 ranged from 100 to $160 \mathrm{~nm}$ in size in previous studies in rat hepatocytes ${ }^{19,40}$ Migration of vesicles of this size along the inner lumen of microvilli, which was below $100 \mathrm{~nm}$ in our preparations (Figure 1), appears barely possible. Lateral diffusion of carrier proteins along microvilli membranes after insertion into the canalicular circumference appears more likely to explain localization of Bsep and Mrp2 on microvilli membranes. Thus, an early increase in membrane density of apical transport proteins should occur at the canalicular circumference rather than on microvilli membranes in cholestatic hepatocytes after exposure to an anticholestatic agent.

In conclusion, the present data provide further evidence for inverse post-transcriptional regulation of apical carrier insertion/retrieval by the cholestatic bile acid, TLCA, and the anticholestatic bile acid, TUDCA. As the bile salt and conjugate export pumps, Bsep and Mrp2, are regarded as key contributors to bile formation, these findings further support the hypothesis that UDCA conjugates may improve impaired bile secretion of the cholestatic liver by stimulating insertion of carrier proteins into the canalicular hepatocyte membrane ${ }^{25,41,42}$ The exact molecular mechanisms need to be further elucidated.

\section{Acknowledgements}

This work was supported by Grants Be 1242/5-4 and Be 1242/5-5 (to U.B.) and Do 622/1-3 (to F.D.) from the Deutsche Forschungsgemeinschaft. The data were partly presented at the 54th Annual Meeting of the American Association for the Study of Liver Diseases, Boston, MA, October 27, 2003, and were published in part in abstract form in Hepatology 2003; 38: 688A. Selected data from Beuers et $\mathrm{al}^{7}$ are presented at the specific request of the Editors, so as to facilitate ready comparison of previously published data on Mrp2 with the new data on Bsep.

\section{References}

1 Paumgartner G, Beuers U. Mechanisms of action and therapeutic efficacy of ursodeoxycholic acid in cholestatic liver disease. Clin Liver Dis 2004;8:67-81.

2 Kitani K. Hepatoprotective Effect of Ursodeoxycholate in Experimental Animals. Kluwer: Dordrecht, NL, 1990.

3 Beuers U, Boyer JL, Paumgartner G. Ursodeoxycholic acid in cholestasis: potential mechanisms of action and therapeutic applications. Hepatology 1998;28: 1449-1453.

4 Trauner M, Graziadei IW. Review article: mechanisms of action and therapeutic applications of ursodeoxycholic acid in chronic liver diseases. Aliment Pharmacol Ther 1999;13:979-996.

5 Lazaridis KN, Gores GJ, Lindor KD. Ursodeoxycholic acid 'mechanisms of action and clinical use in hepatobiliary disorders'. J Hepatol 2001;35:134-146.

6 Haussinger D, Kurz AK, Wettstein M, et al. Involvement of integrins and Src in tauroursodeoxycholateinduced and swelling-induced choleresis. Gastroenterology 2003;124:1476-1487.

7 Beuers U, Bilzer M, Chittattu A, et al. Tauroursodeoxycholic acid inserts the apical conjugate export pump, Mrp2, into canalicular membranes and stimulates organic anion secretion by protein kinase C-dependent mechanisms in cholestatic rat liver. Hepatology 2001; 33:1206-1216.

8 Beuers U, Denk GU, Soroka CJ, et al. Taurolithocholic acid exerts cholestatic effects via phosphatidylinositol 3-kinase-dependent mechanisms in perfused rat livers and rat hepatocyte couplets. J Biol Chem 2003;278: 17810-17818.

9 Milkiewicz P, Roma MG, Elias E, et al. Hepatoprotection with tauroursodeoxycholate and beta muricholate against taurolithocholate induced cholestasis: involvement of signal transduction pathways. Gut 2002;51: 113-119.

10 Gerloff T, Stieger B, Hagenbuch B, et al. The sister of Pglycoprotein represents the canalicular bile salt export pump of mammalian liver. J Biol Chem 1998;273: 10046-10050.

11 Schliess F, Kurz AK, vom Dahl S, et al. Mitogenactivated protein kinases mediate the stimulation of bile acid secretion by tauroursodeoxycholate in rat liver. Gastroenterology 1997;113:1306-1314.

12 Kurz AK, Graf D, Schmitt M, et al. Tauroursodesoxycholate-induced choleresis involves p38(MAPK) activation and translocation of the bile salt export pump in rats. Gastroenterology 2001;121:407-419.

13 Kubitz R, Sutfels G, Kuhlkamp T, et al. Trafficking of the bile salt export pump from the Golgi to the canalicular membrane is regulated by the p38 MAP kinase. Gastroenterology 2004;126:541-553.

14 Denk GU, Kiemer AK, Wimmer R, et al. Tauroursodeoxycholic acid stimulates bile flow and organic anion secretion independently of mitogen-activated protein kinases Erk 1/2 in the cholestatic rat liver. Hepatology 2001;34:508A. 
15 Wimmer R, Hohenester S, Denk GU, et al. Role of p38 MAPK in TUDCA-induced bile formation in cholestatic liver. J Hepatol 2004;40(Suppl.1):25.

16 Kipp H, Arias IM. Newly synthesized canalicular ABC transporters are directly targeted from the Golgi to the hepatocyte apical domain in rat liver. J Biol Chem 2000;275:15917-15925.

17 Wang L, Boyer JL. The maintenance and generation of membrane polarity in hepatocytes. Hepatology 2004; 39:892-899.

18 Tuma PL, Hubbard AL. Transcytosis: crossing cellular barriers. Physiol Rev 2003;83:871-932.

19 Soroka CJ, Pate MK, Boyer JL. Canalicular export pumps traffic with polymeric immunoglobulin A receptor on the same microtubule-associated vesicle in rat liver. J Biol Chem 1999;274:26416-26424.

20 Zinchuk V, Zinchuk O, Okada T. Experimental LPSinduced cholestasis alters subcellular distribution and affects colocalization of Mrp2 and Bsep proteins: a quantitative colocalization study. Microsc Res Tech 2005;67:65-70.

21 Layden TJ, Boyer JL. Influence of bile acids on bile canalicular membrane morphology and the lobular gradient in canalicular size. Lab Invest 1978;39: 110-119.

22 Buscher HP, Schramm U, MacNelly S, et al. The acinar location of the sodium-independent and the sodiumdependent component of taurocholate uptake. A histoautoradiographic study of rat liver. J Hepatol 1991;13:169-178.

23 Weibel ER, Kistler GS, Scherle WF. Practical stereological methods for morphometric cytology. J Cell Biol 1966;30:23-38.

24 Weibel ER. Stereological principles for morphometry in electron microscopic cytology. Int Rev Cytol 1969; 26:235-302.

25 Beuers U, Nathanson MH, Isales CM, et al. Tauroursodeoxycholic acid stimulates hepatocellular exocytosis and mobilizes extracellular $\mathrm{Ca}^{++}$mechanisms defective in cholestasis. J Clin Invest 1993;92:2984-2993.

26 Kurz AK, Block C, Graf D, et al. Phosphoinositide 3kinase-dependent Ras activation by tauroursodesoxycholate in rat liver. Biochem J 2000;350(Part 1): 207-213.

27 Misra S, Ujhazy P, Gatmaitan Z, et al. The role of phosphoinositide 3-kinase in taurocholate-induced trafficking of ATP-dependent canalicular transporters in rat liver. J Biol Chem 1998;273:26638-26644.

28 Misra S, Ujhazy P, Varticovski L, Arias IM. Phosphoinositide 3-kinase lipid products regulate ATP-dependent transport by sister of P-glycoprotein and multidrug resistance associated protein 2 in bile canalicular membrane vesicles. Proc Natl Acad Sci USA 1999;96:5814-5819.
29 Anwer MS. Cellular regulation of hepatic bile acid transport in health and cholestasis. Hepatology 2004; 39:581-590.

30 Beuers U, Throckmorton DC, Anderson MS, et al. Tauroursodeoxycholic acid activates protein kinase C in isolated rat hepatocytes. Gastroenterology 1996;110: 1553-1563.

31 Stravitz RT, Rao YP, Vlahcevic ZR, et al. Hepatocellular protein kinase $\mathrm{C}$ activation by bile acids: implications for regulation of cholesterol 7 alphahydroxylase. Am J Physiol 1996;271:G293-G303.

32 Bouscarel B, Kroll SD, Fromm H. Signal transduction and hepatocellular bile acid transport: cross talk between bile acids and second messengers. Gastroenterology 1999;117:433-452.

33 Noe J, Hagenbuch B, Meier PJ, et al. Characterization of the mouse bile salt export pump overexpressed in the baculovirus system. Hepatology 2001;33:1223-1231.

34 Kubitz R, Saha N, Kuhlkamp T, et al. Ca2+-dependent protein kinase $\mathrm{C}$ isoforms induce cholestasis in rat liver. J Biol Chem 2004;279:10323-10330.

35 Tuma PL, Nyasae LK, Hubbard AL. Nonpolarized cells selectively sort apical proteins from cell surface to a novel compartment, but lack apical retention mechanisms. Mol Biol Cell 2002;13:3400-3415.

36 Wakabayashi Y, Lippincott-Schwartz J, Arias IM. Intracellular trafficking of bile salt export pump (ABCB11) in polarized hepatic cells: constitutive cycling between the canalicular membrane and rab11-positive endosomes. Mol Biol Cell 2004;15:3485-3496.

37 Kikuchi S, Hata M, Fukumoto K, et al. Radixin deficiency causes conjugated hyperbilirubinemia with loss of Mrp2 from bile canalicular membranes. Nat Genet 2002;31:320-325.

38 Crawford AR, Smith AJ, Hatch VC, et al. Hepatic secretion of phospholipid vesicles in the mouse critically depends on mdr2 or MDR3 P-glycoprotein expression. Visualization by electron microscopy. J Clin Invest 1997;100:2562-2567.

39 Crawford JM, Mockel GM, Crawford AR, et al. Imaging biliary lipid secretion in the rat: ultrastructural evidence for vesiculation of the hepatocyte canalicular membrane. J Lipid Res 1995;36:2147-2163.

40 Crawford JM. Role of vesicle-mediated transport pathways in hepatocellular bile secretion. Semin Liver Dis 1996;16:169-189.

41 Haussinger D, Saha N, Hallbrucker C, et al. Involvement of microtubules in the swelling-induced stimulation of transcellular taurocholate transport in perfused rat liver. Biochem J 1993;291:355-360.

42 Crawford JM, Strahs DC, Crawford AR, et al. Role of bile salt hydrophobicity in hepatic microtubuledependent bile salt secretion. J Lipid Res 1994;35: 1738-1748. 